\section{Anaesthesia and ophthalmic surgery}

Acharya S

Consultant Anaesthetist

University Hospital Aintree, Liverpool, UK

Dear Editor,

The first issue of the Nepalese Journal of Ophthalmology was forwarded to me by one of my anaesthetist colleagues here in the UK. I thoroughly enjoyed reading 2 articles related to my specialty of anaesthesia. Both articles (Bhattarai 2009 and Tuladhar et al 2009) are of very high standard. They and you and the entire team should be congratulated for such a high quality journal.

I have been very encouraged by the academic development in Nepal in last two decades. Please pass on my congratulations to everyone involved in this venture.
Correspondence to

Dr Shambhu Acharya, MD, FRCA

ConsultantAnaesthetist

University Hospital Aintree

Liverpool, UK

E-mail: spacharya1958@yahoo.co.uk

\section{References}

Bhattarai BK (2009). Monitored anaesthesia care and ophthalmic surgery. Nep J Oph; 1: 60-65.

Tuladhar S (2009). Effectiveness of sedation in dacryocystorhinostomy surgery. Nep J Oph; 1:2531 .

Source of support: nil. Conflict of interest: none

\title{
Errata
}

The composition of the Advisory Board (Nep J Oph

2009; 1(1) has been corrected as follows.

Canada

Martin Spencer, MD

The Netherlands

Folkert Tegelberg, MD 